\title{
A Review of Methodological Choices Relating to Work-Life Boundary Research
}

\author{
Sulakshana De Alwis \\ Stockholm University, Sweden, sulakshana@dsv.su.se \\ NSвм Green University, Sri Lanka, sulakshana@nsbm.ac.lk \\ Patrik Hernwall \\ Stockholm University, Sweden \\ hernwall@dsv.su.se
}

\begin{abstract}
A methodological review was performed on work-life boundary-related studies published from the year 2010 to 2018 . This review systematically selected 59 journal articles on the work boundary phenomenon. The selection criteria for this review closely followed three previous systematic methodological reviews performed on work-life research. Where possible, comparisons were made to integrate the findings of the current study with these previous systematic reviews. Articles were reviewed based on methodological choices such as research design, sampling strategy, data collection, data analysis, reliability, and validity measures. Findings of the review revealed that researchers had utilised a variety of methodological stances to conduct their studies. The majority of the studies in the field followed a quantitative approach, and most studies relating to work boundary management were field studies with a cross-sectional design. Qualitative studies in the area were primarily based on grounded theory. Significant methodological gaps were identified that could be bridged by future studies. Further, notable suggestions were proposed relating to reliability and validity measures taken by the researchers.
\end{abstract}

Key Words: work-life boundary management, boundary theory, integration, segmentation, work-life balance, work-life conflict, work-family

JEL Classification: 015, M54

(c) BY-SA https://doi.org/10.26493/1854-6935.19.73-101

\section{Introduction}

Empirical studies on work and family research is not a new phenomenon; in fact, over the last three decades, work-family research has gained much popularity among work and organisational psychology researchers (Allen and Martin 2017). Work-life issues have become a notable rhetoric among the media, business circles, and the political world in the 21st century. 
Hence, the development of work-family/life balance policies is a high priority in an organisations' human resource agenda (Chang, McDonald, and Burton 2010). This emphasis has led academics to produce new theoretical and conceptual orientations regarding work-life balance, such as work-life conflict, work-life balance, and work-life boundary management (Eby et al. 2005).

The literature on work-life issues has progressed with changes in the world of work. Most recent literature on work-life issues has focused on demographic changes (e.g. increasing female employment, dual-earner couples, same-sex marriages, single parents) in the workforce and the rapid development of technology (e.g. teleworking, portable work, smartphone use) (Allen and Martin 2017; Gadeyne et al. 2018). These fundamental changes in work and family lives have created more research areas to investigate (Allen and Martin 2017; Chang, McDonald, and Burton 2010). In the recent past, the focus of work-life research expanded to the individual level (Kreiner, Hollensbe, and Sheep 2009). The researchers focused on studying how individuals perceive and manage their work and nonwork roles. As a result, the work boundary theory emerged as a primary theoretical underpinning to discuss individual experiences in managing work and other life roles (Rothbard and Ollier-Malaterre 2015).

This paper intends to evaluate the methodological choices of work boundary research. Despite earlier reviews related to work-life research, no prominent reviews of work boundary management's methodological choices are available. This review will systematically evaluate the validity, reliability, and trustworthiness of the previous empirical studies related to work-boundary management. This review will also help profile the methodological choices in work boundary management research, thereby assisting researchers in understanding the methodological gaps in the field. The rest of the paper is arranged as follows: the next section will discuss the theoretical base related to this study, followed by the methods section. The following section will present the results of the systematic review. In the final two sections, implications will be discussed, with suitable recommendations.

\section{Theoretical Background}

WORK BOUNDARY MANAGEMENT

Work boundary management is a subarea of work-life balance research and has emerged as a field of interest in the past two decades (Roth- 
bard and Ollier-Malaterre 2015). Boundary management is a broad conceptualisation that describes the multiple life roles of people and how they prefer to manage these relationships. Hence, people create, modify, and maintain mental boundaries between their different life roles to understand and manage their surroundings (Ashforth, Kreiner, and Fugate 2000). This attempt to manage different life roles is often referred to as integration and segmentation preference of life domains. Integration preference (permeable) allows elements from one life domain to flow or mix with another, while segmentation preference (non-permeable) blocks the flow or mix of elements from one life domain to another (Kreiner, Hollensbe, and Sheep 2009).

Work boundary management considers work-life balance or conflict from a different perspective than the traditional conflict-based perspective. Work boundary theory goes beyond the traditional conflict model, which discusses the spillover of work demands to non-work spheres and vice versa (Kreiner, Hollensbe, and Sheep 2009; Clark 2000). According to the work boundary theory, people experience conflict between work and non-work domains when they cannot maintain their preferred boundaries (i.e. segmentation or integration) between work and nonwork domains. In other words, work-life conflict occurs when there is incongruence between actual and preferred boundaries, whereas work-life balance occurs when an individual feels that they can enact the boundaries they prefer between work and non-work domains (Ammons 2013). Work boundary management is the decision-making process involved in maintaining preferred boundaries between multiple life domains (Rothbard and Ollier-Malaterre 2015).

The emerging trend of boundary management theories on worklife balance studies rightly coincides with the social and technological changes in the world of work. Due to globalisa-tion and the rapid growth of information communication technologies, people can connect with their workplaces at any given time (Golden and Geisler 2007). This constant engagement with the workplace has promoted the integration of multiple life roles in everyday life, and consequently, these developments have caused many challenges and opportunities for individuals to manage their boundaries between work and non-work lives. In particular, smartphones have blurred the boundaries between work and non-work life domains, and have led people to actively manage their boundaries between work and non-work domains (Derks et al. 2016). Thus far, studies have revealed that the employees' boundary management process could 
have a significant impact on productivity, commitment, interpersonal relationships, and wellbeing (Rothbard and Ollier-Malaterre 2015).

Although researchers have shown increased attention to work-boundary theory in the recent past, further empirical studies are required to fully understand how people create, maintain and modify boundaries between work and non-work domains (Rothbard and Ollier-Malaterre 2015; Allen, Cho, and Meier 2014). So far, studies have discussed people's boundary preferences and how it affects their work-life experiences extensively (Allen, Cho, and Meier 2014; Rothbard and Ollier-Malaterre 2015). Further, a separate set of studies focus on how people manage their work-life boundaries using different boundary management strategies (Kreiner, Hollensbe, and Sheep 2009; Kossek et al. 2012). Researchers have also studied the roles of different boundary participants in the boundary management process, such as managers, co-workers, and family members (Kreiner, Hollensbe, and Sheep 2009; Kossek et al. 2012).

However, with the advent of new communication technologies, the process of boundary management has become more challenging to people (Adisa, Gbadamosi, and Osabutey 2017). Hence, researchers need to pay more specific attention to how technology has changed the world of work and thereby challenged peoples' work-life boundaries (Adisa, Gbadamosi, and Osabutey 2017; Ollier-Malaterre, Jacobs, and Rothbard 2019). Moreover, researchers need to conceptualise the non-work lives of people beyond their families, to understand how people manage boundaries between work and other non-work life domains, such as spiritual life, friendship and education (Rothbard and Ollier-Malaterre 2015). Further, many of the studies in this area have focused on western settings; more studies from various social, economic and cultural settings would enhance the current understanding in this area (Ollier-Malaterre, Jacobs, and Rothbard 2019).

\section{METHODOLOGICAL CHOICES IN WORK-LIFE RESEARCH}

In any empirical study, the methodological choices are an essential aspect as it provides a proper guideline to understanding the phenomenon under investigation. Most researchers develop their methodological decisions based on the findings and insights provided in previous studies. Hence, researchers must understand the methodological choices relating to their research question. In terms of work-life research, some methodological reviews talk about the methodological foundations followed by earlier studies. Among these studies, Casper et al's (2007) review on work-family research methods between $1980-2003$ provides an excel- 
lent summary of different methodological choices and their effectiveness. This study discussed sample characteristics, research design, data collection, triangulation, data analysis, and variable measurements as critical methodological choices (Casper et al. 2007). Chang, McDonald, and Burton (2010) also performed a similar study, reviewing work-life literature from 1987 to 2006. One advancement of the review by Chang, McDonald, and Burton (2010) is that they discussed the differences between workfamily conflict and work-life balance, which are two constructs used interchangeably in work-life research.

The chapter written by Lapierre and McMullan (2015) in the Oxford Handbook of Work and Family is one of the most recent methodological reviews in this area, focusing on work-family literature published between 2004 to 2013. In this study, they also reviewed methodological choices relating to sampling, research design, data collection, outcome measurement, multiple sources, triangulation, and level of analysis. The review indicated that qualitative and multi-wave studies have increased compared to the review of Casper et al. (2007). Another notable methodological review in work-family research is the methodological paper of Beigi and Shirmohammadi (2017). Here, they analysed the qualitative methodologies adopted in work-family research and found that work-life researchers have ample room in utilising different qualitative methodologies in their research.

This review extends the methodological discussion initiated in previous reviews specifically focusing on the work boundary-related research studies. As there is no notable methodological review on work boundary management, on the one hand, this review compared methodological choices of work-life research with the studies related to work-boundary research. On the other hand, this review critically evaluated the methodological choices in work boundary research. Such discussion will fill the current gap in the literature on methodological choices in work boundary research, which will ultimately advance the methodological rigour of work boundary research.

\section{Method}

LITERATURE SELECTION AND CRITERIA FOR STUDY INCLUSION

A systematic literature search was conducted to identify peer-reviewed journal articles published from 2010 to 2018 . Two manual searches were performed in Google Scholar and the E B sco discovery service. 


\section{Google Scholar search}

The first search was performed in Google Scholar using the algorithmic rules provided in Google Scholar. For this search, we needed to find articles that discuss both boundary management and work-life issues. Therefore, the keywords included the main concepts in boundary management and work-family issues. Accordingly, the following advanced keyword search was performed in Google Scholar:

('Boundary management' OR 'boundary theory' OR 'border theory' OR 'integration' OR 'segmentation') ('Work-life balance' or 'work-life conflict' o R 'work-family conflict' o 'Work-life').

The initial results of the search yielded 19,500 articles from various journals and sources. Secondly, search results were limited to articles published after 2010, which reduced the number of articles to 18,200 . This reduction clearly shows that work boundary management has been propelled in work-family research in the last eight years. In order to further refine the search into credible articles, we followed the inclusion criteria utilised by Casper et al. (2007), Lapierre and McMullan (2015), and Beigi and Shirmohammadi (2017). These review papers only selected articles from high impact journals from the industrial and organisational area for their reviews. Usually, high impact journals only accept publications of highly acclaimed and reputed academics in the area of focus, due to their content standards and topical focus. The following journals were selected based on the inclusion criteria:

- Academy of Management Journal

- Administrative Science Quarterly

- Group and Organization Management

- Human Resource Management Journal

- Human Relations

- Journal of Applied Psychology

- Journal of Business and Psychology

- Journal of Management

- Journal of Occupational Health Psychology

- Journal of Occupational and Organizational Psychology

- Journal of Organizational Behavior

- Journal of Vocational Behaviour

- Organisational Behaviour and Human Decision Process 
TA B LE 1 Frequency of Search Results by Journal (Google Search)

\begin{tabular}{lr}
\hline Journal title & Frequency \\
\hline Academy of Management Journal & 64 \\
Administrative Science Quarterly & 13 \\
Group and Organization Management & 0 \\
Human Resource Management Journal & 76 \\
Journal of Applied Psychology & 102 \\
Journal of Business and Psychology & 54 \\
Journal of Management & 136 \\
Journal of Occupational Health and Psychology & 109 \\
Journal of Occupational and Organizational Psychology & 33 \\
Personnel Psychology & 58 \\
Journal of Organisational Behavior & 115 \\
Journal of Vocational Behavior & 164 \\
Organizational Behavior and Human Decision Process & 0 \\
Work and Stress & 0 \\
Personnel Review & 85 \\
Human Relations & 121 \\
The International Journal of HRM & 301 \\
\hline Total & 1,431 \\
\hline
\end{tabular}

- Personnel Psychology

- Personnel Review

- The International Journal of Human Resource Management

- Work and Stress

This inclusion criterion will enhance the comparability of the results of this study with the reviews mentioned above. The above-mentioned advanced keyword search was supplement-ed with Source: '«journal name»"

Table 1 presents the results for each journal in the keyword search performed in Google scholar. A total of 1,431 articles were scanned for relevance based on title and abstract. Articles that are not related significantly to boundary management were then excluded, along with literature reviews and meta-analysis papers. Finally, 40 articles were selected for the final analysis (Trefalt 2013; Reyt and Wiesenfeld 2015; Derks et al. 2016; Cruz and Meisenbach 2018; Sanz-Vergel et al. 2011; Liu et al. 2013; Daniel and Sonnentag 2016; Spieler et al. 2017; Methot and LePine 2016; Mc- 
Dowall and Lindsay 2014; Golden 2012; Braukmann et al. 2017; Hunter, Clark, and Carlson 2017; Paustian-Underdahl et al. 2016; Lapierre and Allen 2012; Derks et al. 2015; Kinnunen et al. 2017; Koch and Binnewies 2015; Park, Fritz, and Jex 2011; Derks, van Mierlo, and Schmitz 2014; McNall, Scott, and Nicklin 2015; Carlson et al. 2015; Matthews, BarnesFarrell, and Bulger 2010; Halbesleben et al. 2010; Barber and Santuzzi 2015; Matthews, Winkel, and Wayne 2014; Piszczek 2017; Lapierre et al. 2016; Spieler, Scheibe, and Stamov Roßnagel 2018; Biron and van Veldhoven 2016; Uhlmann et al. 2013; Capitano and Greenhaus 2018; Kossek et al. 2012; Winkel and Clayton 2010; Shockley and Allen 2010; Ammons 2013; Gadeyne et al. 2018; Adisa, Gbadamosi, and Osabutey 2017; Foucreault, Ollier-Malaterre, and Ménard 2016).

\section{EBSCO Discovery Service}

The second search used the EBsco discovery service (EDS) available in the Stockholm University Library. This search engine enables browsing many databases through one gateway. For this study, all databases available in the EDs were included to get an overall availability of studies related to work boundary management.

The advanced search function of the EDS was employed to find related articles for this review. Hence, the following algorithmic statement was run to find articles relating to boundary management and work-life issues:

(work-life balance or work-life conflict or work-family conflict or Work Life) and (boundary management or work-life boundaries OR boundary theory or border theory or integration $\mathrm{OR}$ segmentation).

The initial search of EDS yielded 66,844 articles. However, search results were further refined using the following limiters: published after the year 2010, peer-reviewed articles, and Stockholm university library collection. These limiters reduced the search to 6,404 articles. In the next stage, the search results were narrowed using subject terms available in the EDS for the specified search criteria. All subject terms related to work-life issues and boundary management available in the EDS were included to refine the results. Accordingly, the following subject terms were selected: work-life balance, work, work-life, quality of life, work and family, work environment, quality of work, families, boundaries, work-family conflict, family, labour market, burnout, well-being, working hours, employee attitudes, mental health, leisure, telecommuting, family conflict, 
TABLE 2 Frequency of Selected Articles by Journal

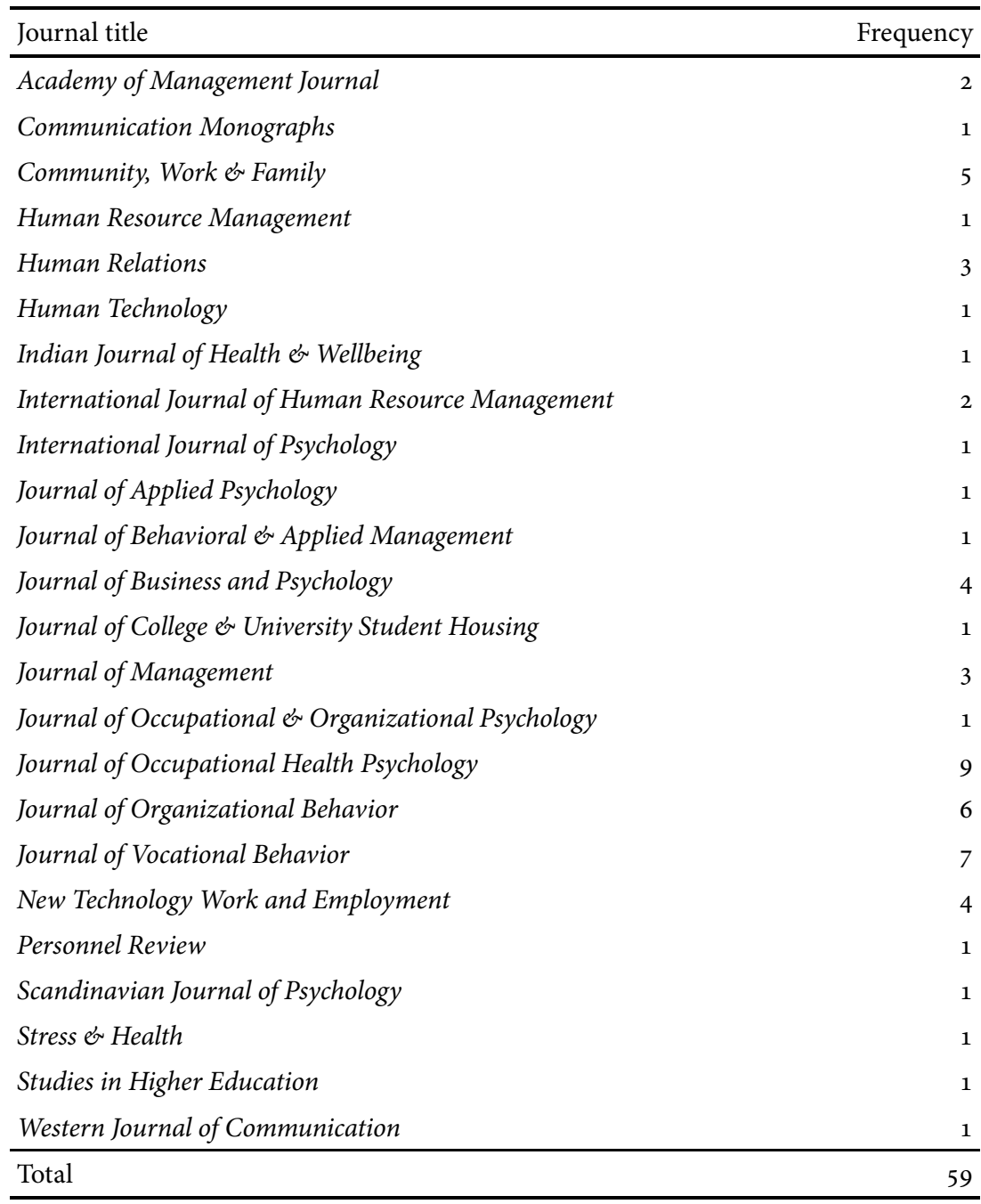

employment, job stress and integration. Further, to retrieve articles available in the English language only, search results were narrowed down by language (i.e. English). This narrowed down the search results to $285 \mathrm{arti}$ cles, which were then subjected to a title and abstract scan; consequently, all articles which were not closely related to work-life boundary management were excluded from the search results. Hence, 19 articles were selected from the EDS search for the final analysis of this review (Golden 2013; Hyland and Prottas 2017; Bailyn 2011; Ba' 2011; Nicholas and Mc- 
Dowall 2012; Lirio 2017; Leung 2011; Bhattacharyya, Suresh, and Selvaraj 2018; Qiu and Fan 2015; Adkins and Premeaux 2014; Rankin and Gulley 2018; Fonner and Stache 2012; Gold and Mustafa 2013; Yeow 2014; Sayah 2013; Pedersen and Jeppesen 2012; Michel and Clark 2013; Ylijoki 2013; Barrett 2014). Based on the above two searches, 59 articles were included in the final analysis of this review. Table 2 presents the frequency of selected articles in the journal.

\section{Content Analysis and Coding Process}

Since this is a methodological review, the content analysis of the selected literature will focus on methodological aspects. We carefully followed the coding schemes used in Casper et al. (2007) and Lapierre and McMullan (2015) to decide the categories and codes for this review. Accordingly, the following categories were used in the coding processes:

- Research design

- Sampling methods

- Data collection methods

- Data analysis methods

- Variable measurement, validity and reliability

Through these, we could effectively understand the research methods used in work-life boundary research. This analysis will act as a guide to understand the current methodological gaps in this research.

\section{RESEARCH DESIGN}

Research design provides an essential framework for the researcher to effectively perform his or her research and significantly guide the data collection and data analysis process (Bryman 2012). For this review, methodological choices around research design were coded as follows. First, the study was coded based on whether it used a quantitative methodology or a qualitative methodology. Secondly, the time horizon was coded, based on multi-wave (longitudinal) or cross-sectional. Finally, articles were coded based on study settings, for instance, if it was a field study or a lab study. Here, a lab study means the study used cases, scenarios, or vignettes to measure the perceptions of respondents.

\section{SAMPLING METHODS}

The generalisability of an empirical study highly depends on the representativeness of the sample. Eight sampling methods were included 
for coding, which covers both probability and non-probability sampling methods. Accordingly, the following sampling methods were used in the content analysis: random, random stratified, random cluster, convenience, snowball, purposive, quota, and respondent-driven. In the case where an article did not provide specific information about the sampling method followed, it was assumed that such studies had used a convenience sampling method (Lapierre and McMullan 2015).

\section{DATA COLLECTION METHODS}

In this review, data collection methods were coded as follows: survey, semi-structured interviews, in-depth interviews, diary, focus group, archival data and other. Further, studies were coded based on the number of sources used to collect data. Accordingly, if a study used multiple sources, it was coded as 'multisource,' and if it used a single source, the code was 'single source.'

\section{DATA ANALYSIS METHODS}

Casper et al.s (2007) coding methodology for data analysis was used in this review to code methodological choices around data analysis.

1. Simple inferential statistics (e.g. correlation, t-tests)

2. Techniques to examine one dependent variable (e.g. Multiple regression, ANOVA)

3. Techniques to examine multiple dependent variables (e.g. MANOvA, MANCOVA)

4. Techniques to examine multiple relations (e.g. structural equation models)

5. Techniques to examine the structure of data (e.g. exploratory factor analysis)

6. Repeated measures (e.g. time series, repeated ANOVA)

7. Qualitative analysis (e.g. content analysis)

Also, within the coding process, specific statistical tests or analysis techniques used in the study were recorded.

VARIABLE MEASUREMENTS, VALIDITY AND RELIABILITY

It is essential to judge whether the correct tools are used to measure the concepts relating to the research study. The following codes helped analyse the variable measurements: existing scale, existing scale adapted, and the new scale used. The generalisability of research findings mainly lies 
with the validity and reliability of information collected (Bryman 2012). In this review, the availability of validity and reliability evidence were coded separately. If the researchers discussed the validity and reliability issues, the specific strategies used to prove validity and reliability were also captured.

\section{Results}

RESEARCH DESIGN

Most investigations in the work boundary management area have used a quantitative approach in their research design (i.e. $70 \%$ or 41 out of 59 ), while $27 \%$ of studies (16 articles) utilised a qualitative approach, and $3 \%$ (2 articles) used a mixed methodology. Regarding time horizon, 64\% (38 articles) used the cross-sectional approach while $36 \%$ (21 articles) collected data, more than once, from respondents (i.e. multi-wave). A majority of the work boundary studies were field studies ( $95 \%$ or 56 articles), two articles (3\%) used lab settings, and one mixed-method study (2\%) adopted both field and lab settings in its work.

\section{SAMPLING METHODS}

Most of the reviewed studies discussed the sample and its characteristics. Thirty-seven articles (63\%) of the review papers used a convenience sampling method, $19 \%$ (11 articles) used non-probability purpose sampling, $12 \%$ ( 7 articles) used the snowball method, and 5\% ( 3 articles) used random sampling.

Further, one mixed-method study used multiple non-random sampling methods for their various studies. No paper in this review employed random cluster, random stratified, or respondent driven methods. Only three papers out of $59(5 \%)$ of the selected studies used the probability sampling method, and out of quantitative studies, $73 \%$ (30 papers out of 41) used a convenience sampling method.

\section{DATA COLLECTION METHODS}

Sixty-three per cent (37 articles) of the studies in this review employed a survey method as the primary data collection strategy, $17 \%$ (10 articles) used a semi-structured interview, and three studies used in-depth interviews.

Further, two selected studies adopted the diary method to collect data. The rest of the studies (10\% or 6 articles) used a mix of methods such as 
open-ended questionnaires and focus groups. In addition, 92\% (54 articles) of the studies collected data from a single source, while $8 \%$ (5 articles) used multiple sources to collect data.

VARIABLE MEASUREMENTS, VALIDITY AND RELIABILITY

Out of 59 articles reviewed, 43 (72\%) used explicit variable measurement methods. Fifty-one per cent ( 22 articles) of the studies that used variable measurement utilised existing scales, while $42 \%$ (18 articles) adapted the existing scales according to their study purposes, while three studies developed new scales for their research.

In terms of validity evidence, $58 \%$ (34 articles) discussed the validity measures taken in the studies, while $42 \%$ ( 25 articles) did not discuss validity measures. Eighty per cent (47 articles) of the papers reported reliability measures taken in the study, while $20 \%$ ( 12 articles) failed to report any reliability evidence. Confirmatory Factor Analysis (CFA) was the most used tool (20 articles or $33 \%$ ) to show the validity of the measurements.

In terms of reliability consideration, the researchers widely adopted Cronbach's alpha for the reliability test. In studies of quantitative nature, 98\% (39 articles out of 41) at least mentioned Cronbach's alpha value as a reliability measure. However, validity evidence was available in $63 \%$ (26 articles out of 41) of quantitative studies.

\section{DATA ANALYTIC METHODS}

Seventy-three per cent ( 43 articles) of the reviewed papers utilised a simple inferential statistcs analysis and report data. Mean, standard deviation, and correlation were the popular inferential statistical tools used by the researchers. Techniques such as multiple hierarchical regression and ANOVA were used by $41 \%$ ( 24 articles) of the studies to report the relationships with the dependent variable, while $3 \%$ ( 2 articles) of the studies used techniques to analyse multiple dependent variables such as MANOVA and MANCOVA. Twenty-four per cent of the papers (14 articles) in the review used data modelling techniques to delineate multiple relations.

Moreover, data structure assessment tools such as CFA were utilised by $37 \%$ ( 22 articles) of the studies, whereas repeated measures such as multilevel modelling for repeated measures were employed by $12 \%$ ( 7 articles) of the studies. Finally, $31 \%$ (18 articles) of the reviewed investigations used qualitative analysis techniques to answer research questions. Grounded 
theory methodology was the most popular qualitative analysis (6 out of 16 articles or $38 \%$ ) or technique utilised by the researchers.

\section{Discussion}

QUANTITATIVE DESIGNS

Similar to the findings of previous systematic reviews (Casper et al. 2007; Lapierre and McMullan 2015) on work-life research, most studies in work-life boundary management have also followed the quantitative approach. These types of positivistic research are widely carried out by researchers, perhaps due to the preoccupied perceptions of such research within the research community (Bryman 2012). The precise measurement of variables, the ability to infer the causality between independent and different variables, and the generalisation and replication of the results are the main preoccupations related to quantitative methodology. These preoccupations are often distinguished as strengths of the quantitative approach.

In the review, it was evident that researchers had attempted to convey these preoccupations to the reader. For example, most of the quantitative studies (40 articles or 97\%) used existing scales or adapted existing scales to measure variables related to work-life boundary management, to convey that they had used an acceptable measurement tool in their studies.

\section{Research Design Issues}

A significant finding of this review is that the majority of the studies followed the cross-sectional design. Using cross-sectional analysis to validate causal inferences is often challenged in academia (Bryman 2012; Lindell and Whitney 2001). In a cross-sectional design, it is difficult to conclude what causes the other, if two factors are associated (Payne and Payne 2004). Cross-sectional designs are more prone to the common method bias than multi-wave designs (Lindell and Whitney 2001). The common method bias means that variances in responses in a study are not attributed to the participants' real predispositions but to the nature of the instrument (Podsakoff et al. 2003). Typically, this could be more prevalent in a cross-sectional study due to recall bias and non-response (McGonagle 2017). As a solution to this methodological challenge, we can see an increasing trend in multi-wave studies in the work boundary management area. For example, in Casper et al's (2007) review on work-life research, only $11 \%$ of the reviewed articles used multi-wave or longitudinal research design. However, in the recent review of Lapierre 
and McMullan (2015), 22\% of the reviewed papers used multi-wave designs. Confirming the increasing trend, 21 out of 59 papers $(36 \%)$ of the current review employed multi-wave designs, and $44 \%$ (21 studies) of the papers which followed a quantitative approach utilised multi-wave designs. However, most of these multi-wave studies were conducted within a short period, such as one week, two weeks, or a few months. Hence, most of the multi-wave studies closely followed the style of a diary study, though it is not explicitly similar to a diary study due to the short time utilised to collect data.

Conversely, common method-bias issues such as social desirability, leniency, harshness, and recall errors could also arise due to the nature of the data collection instrument (McGonagle 2017), and the common method variance is more prevalent in cross-sectional surveys (Podsakoff, MacKenzie, and Podsakoff 2012). In the current review, 63\% (37 out of 59 papers) of the studies used a survey method to collect data. Notably, this is the most popular data collection method in quantitative studies (90\% or 37 articles). Moreover, the survey method is the cheapest and quickest way to collect data from larger samples (Bryman 2012).

Contemporary researchers often use online surveys to administer their studies. In the current review, several studies adopted online surveys to collect data from respondents (Matthews, Barnes-Farrell, and Bulger 2010; Shockley and Allen 2010; Adkins and Premeaux 2014; Derks et al. 2016). Online surveys are gradually becoming more popular among researchers as they can collect data from a geographically diverse sample within a short period, and online survey software is increasingly becoming more user-friendly and attractive to respondents. Besides, online surveys support the data analysis process through the integration of data into the statistical analysis software. Accordingly, free online survey sites significantly reduce the data collection cost associated with research. However, online surveys also face some challenges, such as the lack of a solid sampling frame and ethical issues (Toepoel 2017).

Most studies in this review collected data from a single source. Work boundary management is a phenomenon created through a complex network of relationships between individuals, supervisors, colleagues, family members, and clients. Perhaps it would be more advantageous if data could be gathered from multiple sources relating to the research questions, and self-administrated questionnaires could also lead to some bias mentioned earlier; however, multiple sources could avoid the adverse effects of such bias (Casper et al. 2007; Lapierre and McMullan 2015). 
Lapierre and McMullan (2015) point out that work-life research overrelies on field studies to infer cause and effect. Hence, some of these relationships may not be clear as they are presented in papers. However, there is a unique need for experimental (lab) designs in work-life research to strengthen the relationships identified through fieldwork. In the current review, only two articles utilised experimental-type designs in the work boundary management area. Lapierre and McMullan (2015) suggest that researchers could design field research as a means of experimental design by coupling field studies with organisational interventions on workfamily balance.

\section{Sampling Methods}

Generalisability means that research findings could be extended beyond the particular context in which the research was conducted (Bryman 2012). In other words, the findings should apply to the entire population rather than the sample (Howell 2013). Positivistic researchers argue that generalisability is a critical strength in their research, but the generalisation of the results highly depends on the representativeness of the sample.

A representative sample should adequately represent all aspects of the population, which could be performed via probability sampling techniques to some extent (Bryman 2012). However, the results of the current review lack conviction, as only two out of all the studies adopted a probability sampling frame for their research.

A significant majority of quantitative studies in this review utilised a convenience sampling frame with an effort to add the representative elements of the population through discussing sample characteristics. Due to the practical implications of recruiting respondents, such as availability, willingness and costs, researchers often use convenience sampling in their studies. Convenience sampling allows the researcher to select a sample of respondents they can quickly and affordably access (Etikan, Musa, and Alkassim 2016). However, the disadvantage of this type of nonprobability sampling method is that it limits the generalisability of the results to a broader population. Researchers could reduce this by increasing the variety of sample characteristics; yet it is not a complete solution to the problem (Etikan, Musa, and Alkassim 2016). Nevertheless, studies based on this sampling method could not be rejected based on these grounds. Though the results based on a convenience sample may not be definitive, these studies still provide useful insights on the work boundary management phenomenon. 


\section{Validity and Reliability Measures in Quantitative Studies}

Another vital element in positivistic research is the validity and reliability of measurements. The generalisations made out of quantitative researches presume that they are derived through a meaningful and consistent measurement tool (Suter 2012). In the current review, 98\% (40 of 41 articles) of the quantitative studies reported reliability measures while $63 \%$ (26 of 41 articles) of quantitative papers reported validity evidence. As expected, all studies that discussed reliability had to use Cronbach's alpha level as their guiding tool, as Cronbach's alpha is a good measure of internal consistency under certain circumstances. However, it is not the sole measurement tool available to assess data reliability (Suter 2012; Spiliotopoulou 2009). There were many criticisms on the application of Cronbach's alpha as the sole reliability measure in past studies (Spiliotopoulou 2009; Schmitt 1996; Agbo 2010; Vaske, Beaman, and Sponarski 2017). It is possible to make the criticism that a large number of items in a scale invariably report a higher value of alpha even though data is not consistent in reality.

Further, critics explain that alpha calculation assumes all constructs are unidimensional, which would not be the case in all situations (Spiliotopoulou 2009; Schmitt 1996; Agbo 2010; Vaske, Beaman, and Sponarski 2017). Hence, alpha values could sometimes mask data inconsistencies. Accordingly, critics suggest that researchers should use other tools alongside Cronbach's alpha (Spiliotopoulou 2009; Schmitt 1996; Agbo 2010; Vaske, Beaman, and Sponarski 2017). In terms of validity assessment, most studies that discussed validity evidence have used confirmatory factor analysis (CFA) as the tool to display the validity of their measurement tools. The confirmatory factor analysis is often used to measure the factor structure and the construct validity of a measurement tool (Atkinson et al. 2011). Using CFA first to assess whether the scales are unidimensional or not, and then using Cronbach's alpha test is mostly advised as a good method to test the validity and reliability of a scale (O'Leary-Kelly and Vokurka 1998).

In this review, some studies used exploratory factor analysis (EFA) to check the factorial validity of its scales. However, CFA has a relative strength over EFA as it can assess the overall model fit (O'Leary-Kelly and Vokurka 1998). Only one study among the reviewed articles discussed the criterion validity and discriminant validity of the scales (Kossek et al. 2012). Most studies used existing scales, previously validated, which could 
be a significant factor for the absence of an extensive discussion on the validity of measure.

\section{Data Analytic Strategies}

For data analysis, almost all the quantitative articles reviewed employed simple inferential statistics such as mean, standard deviation, and correlations. However, we cannot use correlations to infer causal relationships (Bryman 2012). In terms of assessing causal relationships between variables, most studies in this review used multiple hierarchical regression as the analytic tool. Further, researchers frequently used path analysis and structural equation modelling to analyse multiple relations between variables. Multilevel modelling for repeated measures was used in most multi-wave studies as the data analysis strategy. It was evident that multilevel modelling had become more popular recently due to the various advantages associated with the strategy (Kenny, Korchmaros, and Bolger 2003). Unlike traditional repeated measures, multi-level models can manage unequal group sizes effectively.

Further, it can examine the effects of various levels in variables nested datasets. Accordingly, multi-level modelling can adjust to avoid any bias and/or error that could arise from the non-independence of observations (Kenny, Korchmaros, and Bolger 2003). As mentioned above, CFA and EFA were used to analyse the factorial structure of data.

\section{QUALITATIVE DESIGNS}

In this review, only 16 out of 59 studies (27\%) used a qualitative approach. Unlike quantitative or positivistic approaches, the qualitative approach would argue that reality is a socially constructed phenomenon (Bryman 2012). The meanings of this word are interpreted by the participants who experienced them (Bryman 2012; Beigi and Shirmohammadi 2017). Work-life boundary management is a complex social phenomenon which involves negotiations with many parties, and traditional surveybased quantitative studies would not be ideal for gaining insights into such a phenomenon. The qualitative approach is more emergent and flexible and better suited to uncover a complex phenomenon such as work boundary management (Beigi and Shirmohammadi 2017).

\section{Research Design and Sampling Methods}

All qualitative studies (16 articles) of this review have followed field design rather than experimental studies. It is possible to see that researchers 
could use an experimental-type design in qualitative studies to test the cause and effect of various relationships in field studies. Further, only three out of nineteen qualitative studies employed a multi-wave method research design. Ideally, qualitative studies could also follow a longitudinal format to understand the changes in people's work boundary experience (Thomson and Holland 2003). In terms of sampling strategy, convenience (7 studies or $44 \%$ ) and purposive (6 studies or $37 \%$ ) sampling methods seem to be the most utilised in the qualitative research related to work boundary management. Also, three qualitative studies (19\%) have utilised the snowball sampling method to recruit respondents. Since interpretivism research employs small samples, these methods are relatively standard within this research paradigm (Saunders, Lewis, and Thornhill 2009). For instance, purposive sampling allows recruiting respondents based on predefined criteria. For a phenomenon like work boundary management, it is occasionally essential to select who would experience boundary management issues, e.g. married couples (Emmel 2013). Hence, purposive sampling might prove ideal for such a setting.

In terms of data collection, most qualitative studies in the review employed semi-structured interviews. Semi-structured interviews allow the researcher to probe deeper into the depth of a phenomenon already discussed in theories, therefore allowing researchers to uncover new insights into existing knowledge (Given 2008).

\section{Data Analytic Strategies}

The grounded theory is the most widely used qualitative data analytic framework (Bryman 2012). In the current review, seven qualitative studies have used a grounded theory approach to analyse data. The grounded theory allows the researcher to develop concepts about the discrete phenomena uncovered through data analysis. These concepts then build into a theory based on the relationships revealed through data. Grounded theory is good at capturing com-plexities of contexts such as work boundary management (Kreiner, Hollensbe, and Sheep 2009). However, there are criticisms of the usage of grounded theory (Bryman 2012). Some critics argue that grounded theory goes against the social constructionist view and tries to objectify people's experiences (Bryman 2012). Accordingly, a new type of grounded theory emerged as a constructivist grounded theory (Mills, Bonner, and Francis 2006). In this review, qualitative articles had used interpretivism techniques, case study approach, and thematic analysis to analyse the collected data. Hence, qualitative re- 
searchers have more ample avenues to follow than traditional grounded theory analysis.

\section{Validity and Reliability Measures in Qualitative Studies}

A positivist critique of the qualitative approach is that the studies are too subjective and difficult to replicate (Bryman 2012). Qualitative research often follows an open process where the researcher has the flexibility to decide the flow and nature of data collection (Morrow 2005). Positivists argue that qualitative data is the researcher's subjective interpretations of the participant's subjective experiences. Hence, the findings of a qualitative study will be subject to the risk of contamination by the researcher's and the participant's bias.

Further, the flexibility of the design process in the qualitative approach makes it relatively impossible to replicate such a study in another context. Ultimately, this challenges the generalisability of qualitative findings. Often, positivist researchers challenge the generalisability of qualitative findings, arguing that the samples are nonrepresentative and the methodology is unstructured (Bryman 2012; Polit and Beck 2010). These arguments against qualitative studies are further strengthened because qualitative papers do not explicitly mention validity and reliability measures as opposed to quantitative papers. In the current review also, only seven articles among the qualitative studies attempted to discuss the validity or reliability-related methodological explanations.

Some postpositivist or interpretivist scholars have put forward alternative frameworks to increase the rigour and trustworthiness of qualitative studies (Malterud 2001; Morrow 2005; Whittemore, Chase, and Mandle 2001; Polit and Beck 2010; Shento 2004). Hence, qualitative researchers need to be aware of the methodological choices they make in various aspects of their research, such as

- Credibility (similar to Internal Validity)

- Transferability (similar to External Validity)

- Dependability (similar to Reliability)

- Confirmability (similar to Objectivity)

Accordingly, researchers must ensure the credibility of their studies through strategies such as employing well-established research methods, reflective commentary, and random sampling. In terms of transferability, qualitative papers should give a detailed description of the context they have studied. Dependability could be ensured using similar methods 
used in related studies. Further, explaining in detail about the methodology adopted in the study also ensures dependability, as it allows others to replicate the study in another context. The qualitative researchers should be reflective of their bias. Reflective discussion on methodological and theoretical choices could avoid, or at least diminish, subjectivity bias in qualitative studies.

\section{MIXED METHODS IN WORK-LIFE BOUNDARY MANAGEMENT}

In the current review, two papers followed mixed methodologies. Mixed methodological studies often follow a pragmatic research philosophy (Saunders, Lewis, and Thornhill 2009). For a phenomenon like work-life balance, this could yield a clearer picture of the phenomenon. A mixedmethod approach often supports the data triangulation concept where data is validated through several sources (Bryman 2012). This could be an ideal methodological choice in a complex phenomenon such as boundary management, which consists of different stakeholders.

Further, this could combine both qualitative and quantitative approaches by trading off the limitations of each approach. However, this does not mean that mixed methods are methodologically superior to single method research. Mixed method research is more challenging to conduct. It often needs more careful design, more time, and more resources than mono-method studies. Ill-designed mixed-method studies could yield unsatisfactory conclusions similar to the ill-defined monomethod study (Bryman 2012). If the researcher utilises a mixed-method research design, they should be ideally competent in quantitative and qualitative methods. Further, it is crucial to supply a detailed explanation of the methodological choices made in mixed-method research.

\section{Conclusion}

This methodological review of studies in the work-life boundary management area provides a clear idea of methodological choices applied by scholars who have studied the phenomenon. This review revealed that researchers used various methodological stances to investigate the worklife boundary phenomenon. However, there are several methodological gaps that future researchers could adopt to develop the work boundaryrelated research field into a more matured field of inquiry.

Quantitative researchers should focus on sampling issues such as representativeness of the sample they chose in the light of the parametric data analytic strategies they adopt in their studies. Random sampling strate- 
gies will be ideal if it is practically feasible to implement. Further, it is recommended to use more multi-wave studies in the field to overcome issues relating to causal inferences in quantitative studies. Quantitative studies in work boundary management should effectively use more multisource approaches, which allow us to find a clearer picture of the complex interactions between different parties in a boundary management context. As suggested by Casper and co-workers (Casper et al. 2007), researchers could employ experimental designs to clarify doubts regarding the relationships uncovered in field studies. It is evident that researchers in the work-life boundary area overly depend on Cronbach's alpha as the sole indicator of reliability. However, researchers must carefully use alpha values to discuss reliability in light of recent criticisms.

Based on this review, qualitative studies have solely used grounded theory as their methodological choice for data analysis. Researchers have ample access to various qualitative methods applicable to analyse qualitative data such as ethnography, interpretative techniques, and narrative analysis. Further, researchers could use multiple data sources such as focus groups to study data rather than overly relying on semi-structured interviews. It is imperative that qualitative researchers clearly explain and justify the methodological choices in their papers. This explanation would help ensure the validity and reliability of the qualitative study. Moreover, researchers could also adopt mixed methodological designs to study the work boundary phenomenon.

This review has several limitations. In order to limit the number of studies reviewed to a feasible number, we chose articles only from toptier research journals and databases related to the work boundary phenomenon. A more extensive range of journals could have further enhanced the findings of this review. Despite these limitations, this review provides an ideal way forward for future scholars planning to study the work-life boundary phenomenon.

\section{References}

Adisa, T. A., G. Gbadamosi, and E. L. C. Osabutey. 2017. 'What Happened to the Border? The Role of Mobile Information Technology Devices on Employees' Work-Life Balance.' Personnel Review 46 (8): 1651-71.

Adkins, C. L., and S. A. Premeaux. 2014. 'The Use of Communication Technology to Manage Work-Home Boundaries'. Journal of Behavioral and Applied Management 15 (2): 82-100.

Agbo, A. A. 2010. 'Cronbach's Alpha: Review of Limitations and Associated Recommendations.' Journal of Psychology in Africa 20 (2): 233-9. 
Allen, T. D., E. Cho, and L. L. Meier. 2014. 'Work-Family Boundary Dynamics.' Annual Review of Organizational Psychology and Organizational Behavior 1 (1): 99-121.

Allen, T. D., and A. Martin. 2017. 'The Work-Family Interface: A Retrospective Look at 20 Years of Research in Jон P.' Journal of Occupational Health Psychology 22 (3): 259-72.

Ammons, S. K. 2013. 'Work-Family Boundary Strategies: Stability and Alignment between Preferred and Enacted Boundaries.' Journal of Vocational Behavior 82 (1): 49-58.

Ashforth, B. E., G. E. Kreiner, and M. Fugate. 200o. 'All in a Day's Work: Boundaries and Micro Role Transitions.' Academy of Management Review 25 (3): 472-91.

Atkinson, T. M., B. D. Rosenfeld, L. Sit, T. R. Mendoza, M. Fruscione, D. Lavene, M. Shaw, Y. Li, J. Hay, C. S. Cleeland, H. I. Scher, W. S. Breitbart, and E. Basch. 2011. 'Using Confirmatory Factor Analysis to Evaluate Construct Validity of the Brief Pain Inventory (в РI)'. Journal of Pain and Symptom Management 41 (3): 558-65.

Ba', S. 2011. 'Symbolic Boundaries: Integration and Separation of Work and Family Life.' Community, Work \& Family 14 (3): 317-34.

Bailyn, L. 2011. 'Redesigning Work for Gender Equity and Work-Personal Life Integration.' Community, Work \& Family 14 (1): 97-112.

Barber, L. K, and A. M. Santuzzi. 2015. 'Please Respond AS A P: Workplace Telepressure and Employee Recovery'. Journal of Occupational Health Psychology 20 (2): 172-89.

Barrett, A. K. 2014. 'Breaking Boundaries: Temporality and Work-Life Practices in Hospital Organizations.' Western Journal of Communication 78 (4): 441-61.

Beigi, M., and M. Shirmohammadi. 2017. 'Qualitative Research on WorkFamily in the Management Field: A Review.' Applied Psychology 66 (3): $382-433$.

Bhattacharyya, A., A. Suresh, and J. T. Selvaraj. 2018. 'Contextualizing Polychronicity: Integrating Work and Non-Work Domains.' Indian Journal of Health and Wellbeing 9 (1): 19-24.

Biron, M., and M. van Veldhoven. 2016. 'When Control Becomes a Liability Rather Than an Asset: Comparing Home and Office days Among PartTime Teleworkers.' Journal of Organizational Behavior 37 (8): 1317-37.

Braukmann, J., A. Schmitt, L. Duranová, and S. Ohly. 2017. 'Identifying ICT-Related Affective Events across Life Domains and Examining Their Unique Relationships with Employee Recovery.' Journal of Business and Psychology 33 (1): 1-16.

Bryman, A. 2012. Social Research Methods. Oxford: Oxford University Press.

Capitano, J., and J. H. Greenhaus. 2018. 'When Work Enters the Home: 
Antecedents of Role Boundary Permeability Behavior.' Journal of Vocational Behavior 109:87-100.

Carlson, D. S., K. M. Kacmar, S. Zivnuska, and M. Ferguson. 2015. 'Do the Benefits of Family-to-Work Transitions Come at Too Great a Cost?' Journal of Occupational Health Psychology 20 (2): 161-71.

Casper, W. J., L. T. Eby, C. Bordeaux, A. Lockwood, and D. Lambert. 2007. 'A Review of Research Methods in го/ов Work-Family Research.' Journal of Applied Psychology 92 (1): 28-43.

Chang, A., P. McDonald, and P. Burton. 2010. 'Methodological Choices in Work-Life Balance Research 1987 to 2006: A Critical Review. The International Journal of Human Resource Management 21 (13): 2381-413.

Clark, S. C. 200o. 'Work/Family Border Theory: A New Theory of Work/ Family Balance.' Human Relations 53 (6): 747-70.

Cruz, D., and R. Meisenbach. 2018. 'Expanding Role Boundary Management Theory: How Volunteering Highlights Contextually Shifting Strategies and Collapsing Work-Life Role Boundaries.' Human Relations 71 (2): 182-205.

Daniel, S., and S. Sonnentag. 2016. 'Crossing the Borders: The Relationship Between Boundary Management, Work-Family Enrichment and Job Satisfaction.' The International Journal of Human Resource Management 27 (4): 407-26.

Derks, D., A. B. Bakker, P. Peters, and P. van Wingerden. 2016. 'WorkRelated Smartphone Use, Work-Family Conflict and Family Role Performance: The Role of Segmentation Preference.' Human Relations 69 (5): 1045-68.

Derks, D., D. van Duin, M. Tims, and A. B. Bakker. 2015. 'Smartphone Use and Work-Home Interference: The Moderating Role of Social Norms and Employee Work Engagement.' Journal of Occupational and Organizational Psychology 88 (1): 155-77.

Derks, D., H. van Mierlo, and E. B. Schmitz. 2014. 'A Diary Study on WorkRelated Smartphone Use, Psychological Detachment and Exhaustion: Examining the Role of the Perceived Segmentation Norm.' Journal of Occupational Health Psychology 19 (1): 74-84.

Eby, L. T., W. J. Casper, A. Lockwood, C. Bordeaux, and A. Brinley. 2005. 'Work and Family Research in го/ов: Content Analysis and Review of the Literature (1980-2002).' Journal of Vocational Behavior 66 (1): 12497.

Emmel, N. 2013. Sampling and Choosing Cases in Qualitative Research: A Realist Approach. London: Sage.

Etikan, I., S. A. Musa, and R. S. Alkassim. 2016. 'Comparison of Convenience Sampling and Purposive Sampling.' American Journal of Theoretical and Applied Statistics 5 (1): 1-4. 
Fonner, K. L., and L. C. Stache. 2012. 'All in a Day's Work, at Home: Teleworkers' Management of Micro Role Transitions and the Work-Home Boundary.' New Technology, Work and Employment 27 (3): 242-57.

Foucreault, A., A. Ollier-Malaterre, and J. Ménard. 2016. 'Organizational Culture and Work-Life Integration: A Barrier to Employees' Respite?' The International Journal of Human Resource Management 29 (16): 121.

Gadeyne, N., M. Verbruggen, J. Delanoeije, and R. De Cooman. 2018. 'All Wired, All Tired? Work-Related Iст-Use Outside Work Hours and Work-to-Home Conflict: The Role of Integration Preference, Integration Norms and Work Demands.' Journal of Vocational Behavior 107:86-99.

Given, L. M., ed. 2008. The Sage Encyclopedia of Qualitative Research Methods. Thousand Oaks, CA: Sage.

Gold, M., and M. Mustafa. 2013. 'Work Always Wins:' Client Colonisation, Time Management and the Anxieties of Connected Freelancers.' New Technology, Work and Employment 28 (3): 197-211.

Golden, A. G. 2013. 'The Structuration of Information and Communication Technologies and Work-Life Interrelationships: Shared Organizational and Family Rules and Resources and Implications for Work in a High-Technology Organization.' Communication Monographs 80 (1): 101-23.

Golden, A. G, and C. Geisler. 2007. 'Work-Life Boundary Management and the Personal Digital Assistant.' Human Relations 6o (3): 519-51.

Golden, T. D. 2012. 'Altering the Effects of Work and Family Conflict on Exhaustion: Telework During Traditional and Nontraditional Work Hours.' Journal of Business and Psychology 27 (3): 255-69.

Halbesleben, J. R. B., K. L. Zellars, D. S. Carlson, P. L. Perrewé, and D. Rotondo. 2010. 'The Moderating Effect of Work-Linked Couple Relationships and Work-Family Integration on the Spouse Instrumental Support-Emotional Exhaustion Relationship. Journal of Occupational Health Psychology 15 (4): 371-87.

Howell, K. E. 2013. An Introduction to the Philosophy of Methodology. London: Sage.

Hunter, E. M., M. A. Clark, and D. S. Carlson. 2017. 'Violating Work-Family Boundaries: Reactions to Interruptions at Work and Home.' Journal of Management 45 (3): 1284-308.

Hyland, M. A., and D. Prottas. 2017. 'Looking at Spillover from Both Sides: An Examination of Work and Home Flexibility and Permeability' Community, Work \& Family 20 (2): 181-200.

Kenny, D. A., J. D. Korchmaros, and N. Bolger. 2003. 'Lower Level Mediation in Multilevel Models.' Psychological Methods 8 (2): 115-28. 
Kinnunen, U., T. Feldt, J. de Bloom, M. Sianoja, K. Korpela, and S. Geurts. 2017. 'Linking Boundary Crossing from Work to Nonwork to WorkRelated Rumination Across Time: A Variable-and-Person-Oriented Approach.' Journal of Occupational Health Psychology 22 (4): 467-80.

Koch, A. R., and C. Binnewies. 2015. 'Setting a Good Example: Supervisors as Work-Life-Friendly Role Models within the Context of Boundary Management.' Journal of Occupational Health Psychology 20 (1): 82-92.

Kossek, E. E., M. N. Ruderman, P. W. Braddy, and K. M. Hannum. 2012. 'Work-Nonwork Boundary Management Profiles: A Person-Centered Approach.' Journal of Vocational Behavior 81 (1): 112-28.

Kreiner, G. E., E. C. Hollensbe, and M. L. Sheep. 2009. 'Balancing Borders and Bridges: Negotiating the Work-Home Interface via Boundary Work Tactics.' Academy of Management Journal 52 (4): 704-30.

Lapierre, L. M., and T. D. Allen. 2012. 'Control at Work, Control at Home, and Planning Behavior: Implications for Work-Family Conflict.' Journal of Management 38 (5): 1500-16.

Lapierre, L. M., and A. D. McMullan. 2015. 'A Review of Methodological and Measurement Approaches to the Study of Work and Family.' In The Oxford Handbook of Work and Family, edited by T. D. Allen and L. T. Eby, 36-50. Oxford: Oxford University Press.

Lapierre, L. M., E. van Steenbergen, M. C. W. Peeters, and E. S. Kluwer. 2016. 'Juggling Work and Family Responsibilities When Involuntarily Working More from Home: A Multiwave Study of Financial Sales Professionals.' Journal of Organizational Behavior 37 (6): 804-22.

Leung, L. 2011. 'Effects of ICт Connectedness, Permeability, Flexibility, and Negative Spillovers on Burnout and Job and Family Satisfaction.' Human Technology 7 (3): 250-67.

Lindell, M. K., and D. J. Whitney. 2001. 'Accounting for Common Method Variance in Cross-Selectional Research Designs.' Journal of Applied Psychology 86 (1): 114-21.

Lirio, P. 2017. 'Global Boundary Work Tactics: Managing Work and Family Transitions in a 24-7 Global Context.' Community, Work \& Family 20 (1): 72-91.

Liu, J., H. K. Kwan, C. Lee, and C. Hui. 2013. 'Work-to-Family Spillover Effects of Workplace Ostracism: The Role of Work-Home Segmentation Preferences.' Human Resource Management 52 (1): 75-93.

Malterud, K. 2001. 'Qualitative Research: Standards, Challenges, and Guidelines.' The Lancet 358 (9280): 483-8.

Matthews, R. A, J. L. Barnes-Farrell, and C. A. Bulger. 2010. 'Advancing Measurement of Work and Family Domain Boundary Characteristics.' Journal of Vocational Behavior 77 (3): 447-6o.

Matthews, R. A., D. E. Winkel, and J. H. Wayne. 2014. 'A Longitudinal Ex- 
amination of Role Overload and Work-Family Conflict: The Mediating Role of Interdomain Transitions.' Journal of Organizational Behavior 35 (1): 72-91.

McDowall, A., and A. Lindsay. 2014. 'Work-Life Balance in the Police: The Development of a Self-Management Competency Framework.' Journal of Business and Psychology 29 (3): 397-411.

McGonagle, A. 2017. 'Common Method Variance.' In The Sage Encyclopedia of Industrial and Organizational Psychology, 2nd ed., edited by S. Rogelberg, 192-4. Thousand Oaks, CA: Sage.

McNall, L. A, L. D. Scott, and J. M. Nicklin. 2015. 'Do Positive Affectivity and Boundary Preferences Matter for Work-Family Enrichment? A Study of Human Service Workers.' Journal of Occupational Health Psychology 20 (1): 93-104.

Methot, J. R, and J. A. LePine. 2016. 'Too Close for Comfort? Investigating the Nature and Functioning of Work and Non-Work Role Segmentation Preferences.' Journal of Business and Psychology 31 (1): 103-23.

Michel, J. S., and M. A. Clark. 2013. 'Investigating the Relative Importance of Individual Differences on the Work-Family Interface and the Moderating Role of Boundary Preference for Segmentation.' Stress and Health 29 (4): 324-36.

Mills, J., A. Bonner, and K. Francis. 2006. 'The Development of Constructivist Grounded Theory'. International Journal of Qualitative Methods 5 (1): $25-35$.

Morrow, S. L. 2005. 'Quality and Trustworthiness in Qualitative Research in Counseling Psychology'. Journal of Counseling Psychology 52 (2): $250-60$.

Nicholas, H., and A. McDowall. 2012. 'When Work Keeps Us Apart: A Thematic Analysis of the Experience of Business Travellers.' Community, Work \& Family 15 (3): 335-55.

O'Leary-Kelly, S. W., and R. Vokurka. 1998. 'The Empirical Assessment of Construct Validity. Journal of Operations Management 16 (4):387-405.

Ollier-Malaterre, A., J. A. Jacobs, and N. P. Rothbard. 2019. 'Technology, Work, and Family: Digital Cultural Capital and Boundary Management.' Annual Review of Sociology 45 (1): 425-47.

Park, Y., C. Fritz, and S. M. Jex. 2011. 'Relationships between Work-Home Segmentation and Psychological Detachment from Work: The Role of Communication Technology Use at Home.' Journal of Occupational Health Psychology 16 (4): 457-67.

Paustian-Underdahl, S. C., J. R. B. Halbesleben, D. S. Carlson, and K. M. Kacmar. 2016. 'The Work-Family Interface and Promotability: Boundary Integration As a Double-Edged Sword.' Journal of Management 42 (4): $960-81$. 
Payne, G., and J. Payne. 2004. Key Concepts in Social Research. London: Sage.

Pedersen, V. B., and H. J. Jeppesen. 2012. 'Contagious Flexibility? A Study on Whether Schedule Flexibility Facilitates Work-Life Enrichment.' Scandinavian Journal of Psychology 53 (4): 347-59.

Piszczek, M. M. 2017. 'Boundary Control and Controlled Boundaries: Organizational Expectations for Technology Use at the Work-Family Interface.' Journal of Organizational Behavior 38 (4): 592-611.

Podsakoff, P. M., S. B. MacKenzie, L. Jeong-Yeon, and N. P. Podsakoff. 2003. 'Common Method Biases in Behavioral Research: A Critical Review of the Literature and Recommended Remedies.' Journal of Applied Psychology 88 (5): 879-903.

Podsakoff, P. M., S. B. MacKenzie, and N. P. Podsakoff. 2012. 'Sources of Method Bias in Social Science Research and Recommendations on How to Control It.' Annual Review of Psychology 63 (1): 539-69.

Polit, D. F., and C. T. Beck. 2010. 'Generalization in Quantitative and Qualitative Research: Myths and Strategies.' International Journal of Nursing Studies 47 (11): 1451-8.

Qiu, L., and J. Fan. 2015. 'Family Boundary Characteristics, Work-Family Conflict and Life Satisfaction: A Moderated Mediation Model.' International Journal of Psychology 50 (5): 336-44.

Rankin, P. R. IV., and N. Y. Gulley. 2018. 'Boundary Integration and Work/Life Balance When You Live Where You Work: A Study of Residence Life Professionals.' Journal of College and University Student Housing 44 (2): 64-81.

Reyt, J.-N., and B. M. Wiesenfeld. 2015. 'Seeing the Forest for the Trees: Exploratory Learning, Mobile Technology, and Knowledge Workers' Role Integration Behaviors.' Academy of Management Journal 58 (3): 739-62.

Rothbard, N. P., and A. Ollier-Malaterre. 2015. 'Boundary Management.' In The Oxford Handbook of Work and Family, edited by Tammy D. Allen and Lillian T. Eby, 109-22. Oxford: Oxford University Press.

Sanz-Vergel, A. I., E. Demerouti, A. B. Bakker, and B. Moreno-Jiménez. 2011. 'Daily Detachment from Work and Home: The Moderating Effect of Role Salience.' Human Relations 64 (6): 775-99.

Saunders, M., P. Lewis, and A. Thornhill. 2009. Research Methods for Business Students. Harlow: Prentice Hall.

Sayah, S. 2013. 'Managing Work-Life Boundaries with Information and Communication Technologies: The Case of Independent Contractors.' New Technology, Work and Employment 28 (3): 179-96.

Schmitt, N. 1996. 'Uses and Abuses of Coefficient Alpha.' Psychological Assessment 8 (4): $350-3$. 
Shento, A. K. 2004. 'Strategies for Ensuring Trustworthiness in Qualitative Research Projects.' Education for Information 22 (2): 63-75.

Shockley, K. M., and T. D. Allen. 2010. 'Investigating the Missing Link in Flexible Work Arrangement Utilization: An Individual Difference Perspective.' Journal of Vocational Behavior 76 (1): 131-42.

Spieler, I., S. Scheibe, C. Stamov-Roßnagel, and A. Kappas. 2017. 'Help or Hindrance? Day-Level Relationships between Flextime Use, WorkNonwork Boundaries, and Affective Well-Being.' Journal of Applied Psychology 102 (1): 67-87.

Spieler, I., S. Scheibe, and C. Stamov-Roßnagel. 2018. 'Keeping Work and Private Life Apart: Age-Related Differences in Managing the WorkNonwork Interface.' Journal of Organizational Behavior 37 (6): 804-22. Spiliotopoulou, G. 2009. 'Reliability Reconsidered: Cronbach's Alpha and Paediatric Assessment in Occupational Therapy.' Australian Occupational Therapy Journal 56 (3): 150-5.

Suter, W. N. 2012. Introduction to Educational Research: A Critical Thinking Approach. Thousand Oaks, c A: Sage.

Thomson, R., and J. Holland. 2003. 'Hindsight, Foresight and Insight: The Challenges of Longitudinal Qualitative Research.' International Journal of Social Research Methodology 6 (3): 233-44.

Toepoel, V. 2017. 'Online Survey Design.' In The Sage Handbook of Online Research Methods, edited by N. Fielding, R. Lee, and G. Blank, 184-202. London: Sage.

Trefalt, Š. 2013. 'Between You and Me: Setting Work-Nonwork Boundaries in the Context of Workplace Relationships.' Academy of Management Journal 56 (6): 1802-29.

Uhlmann, E. L., E. Heaphy, S. J. Ashford, L. Zhu, and J. Sanchez-Burks. 2013. 'Acting Professional: An Exploration of Culturally Bounded Norms against Nonwork Role Referencing.' Journal of Organizational Behavior 34 (6): 866-86.

Vaske, J. J., J. Beaman, and C. C. Sponarski. 2017. 'Rethinking Internal Consistency in Cronbach's Alpha.' Leisure Sciences 39 (2): 163-73.

Whittemore, R., S. K. Chase, and C. L. Mandle. 2001. 'Validity in Qualitative Research.' Qualitative Health Research 11 (4): 522-37.

Winkel, D. E, and R. W. Clayton. 2010. 'Transitioning between Work and Family Roles As a Function of Boundary Flexibility and Role Salience.' Journal of Vocational Behavior 76 (2): 336-43.

Yeow, J. 2014. 'Boundary Management in an Iст-Enabled Project-Based Organising Context.' New Technology, Work and Employment 29 (3): 237-52.

Ylijoki, O.-H. 2013. 'Boundary-Work between Work and Life in the HighSpeed University'. Studies in Higher Education 38 (2): 242-55. 